\title{
DOIS POEMAS E QUATRO EXPOSIÇÕES J. G. Fichte e H. M. Enzensberger
}

Paulo R. Licht dos Santos*

Apresentamos ao leitor dois poemas: um soneto de Fichte, sem título, de 1963, e um poema "em versos livres" de Hans Magnus Enzensberger, O reino das sombras, escrito em .... Depois de percorrêlos no original em alemão, o leitor irá deparar com três traduções do soneto de Fichte: uma nova e duas já publicadas (uma em português de Paulo César de Souza e outra em francês de A. Philonenko); de Enzensberger encontrará uma tradução inédita, mas apenas uma, por ignorarmos e não termos à mão outra já existente. Por que afinal são aqui postos lado a lado? A nossa aposta é de que assim o leitor se sinta instigado a comparar entre si dois poemas que em muitos aspectos são tão diversos quanto opostos; talvez então ele julgue valer a pena deterse sobre um ou outro aspecto, tirar suas próprias conclusões ou até mesmo lançar-se a outra tradução. Por fim, na última parte, à espera desse leitor, ou melhor, colocando-nos temerariamente na sua posição, arriscaremos algumas considerações, aliás, bastante breves e primárias, segundo os muitos sentidos que essa palavra possa assumir1.

\footnotetext{
Professor Adjunto do Departamento de Filosofia da UFSCar.

${ }^{1}$ Foi de Márcio Suzuki a feliz sugestão de fazer acompanhar a minha tradução do soneto de Fichte com a de Paulo César de Souza, que gentilmente autorizou sua republicação. Registre-se aqui meu agradecimento a ambos.
} 


\section{J. G. FICHTE \\ Soneto (1802) ${ }^{2}$}

Was meinem Augen dieses Kraft gegeben

Dass alle Misgestalt inm is zerronnen

Dass inm die Nächte werden heitre Sonnen

Unordnung Ordnung, und Verwesung Leben?

Was durch der Zeit des Rams verworr'nes Weben

Mich selber leitet hin zum ew'gen Bronnen,

Des Schönen Wahren, Guten und der Wonnen

Und drin vernichtend eintaucht all mein Streben:

Das ist's Seit in Urania's Auge die tiefe

Sich selber klare, blaue, stille, reine

Lichtflamm, ich selber still hineinengesehen;

Seitdem ruht dieses Aug'mir in der Tiefe

Und ist in meinem Seyn - das ewig Eine

Lebt mir im Leben, sieht in meinem sehen.

${ }^{2} \mathrm{O}$ soneto se encontra em Fichte, J. G. Fichtes Werke. Vol. 8. Berlin: Walter de Gruyter, 1971, p.461-2. 


\section{TRADUÇÕES}

\section{FICHTE}

Soneto (1802)

Que me teria dado ao olhar um tal poder,

Que tudo o que é disforme a nada enfim reduz, Que as noites transfigura em sóis de clara luz,

Desordem em ordem torna e definhar, viver?

Que, pelo espaço e tempo enleados no tecer, Ali, à fonte eterna a salvo me conduz,

A fonte o Belo, o Vero, o Bem, Prazer produz, $\mathrm{Na}$ qual desfeito inteiro imerge o meu querer?

É assim por ter eu mesmo quieto adentro olhado No olhar de Urânia a flama-luz a si incender Profunda e azul e quieta em pura claridade.

É assim que tal olhar profundo em mim pousado Reside e em meu Ser é. Por isso vê em meu ver E vive em meu viver - a eterna Unidade.

Trad. Paulo R. Licht dos Santos 
2.

O que empresta ao meu olhar esse vigor,

Que todos os senões the parecem pequenos

$E$ as noites se transformam em sóis serenos,

Em vida a negação, em solidez o tremor?

O que, a confusa teia do tempo a transpor,

Conduz-me certeiro às fontes perenes

Do belo, do vero, de bondade e acenos,

E lá afunda, e aniquila, do meu empenho a dor?

Já sei. Desde que, no olho de Urânia, acesa

Em quietude, pude eu mesmo interiormente

A clara, fina, pura flama azul observar;

Desde então tal visão me habita em profundeza

E é no meu ser - eterna, unicamente;

Vive no meu viver, olha no meu olhar.

Trad. de Paulo César de Souza. ${ }^{3}$

${ }^{3}$ Fichte, J. G. Soneto. Trad.de P. C. Souza. In: Folhetim (Folha de São Paulo), n.593, p.12, 27 maio, 1988 .

104 
D' où vient cette force, dont mon œil est empli,

Telle qu'elle dissipe toute difformité

Et les nuits en soleils radieux métamorphose,

Faisant du désordre naître l'ordre, e du mort la vie?

En l'indecis tissage du temps e de l'espace,

Qui me conduit vers les fontaines éternelles

Du beau, du Vrai, du Bien, purifiant mon élan fini

En un joie où il trouve son baptême?

Un jour, j'ai laissé mon regard pénetrer dans l' œil d'Uranie,

La profonde, calme, claire, bleue et pure

Flamme de lumière qui par Soi s'éclaire.

Depuis repose au fond de moi cet œil

Et il est en mon être, - l'Éternel

Dans ma vie s'accomplit e par mes yeux regarde.

Trad. de Alexis Philonenko ${ }^{4}$

${ }^{4}$ In: Fichte, F. G. Doctrine de la Science et textes anexes. Trad. de A. Philonenko. Paris: Vrin, 1987, p. 191 


\section{H. M. ENZENSBERGER}

Schattenreich ${ }^{4}$

I

Hier sehe ich noch einen Platz, einen freien Platz,

hier im Schatten.

II

Dieser Schatten

ist nich zu verkaufen.

III

Auch das Meer

wirft vielleicht einen Schatten, auch die Zeit.

IV

Die Kriege der Schatten

sind Spiele:

kein Schatten

steht dem andern im Licht.

V

Wer im Schatten wohnt, ist schwer zu töten.

${ }^{4}$ Este poema se encontra em Enzensberger, H.M. Gedichte 1950-2000. Frankfurt am Main: Suhrkamp Verlag, 2001.

106 
VI

Für eine Weile

Trete ich aus meinem Schatten,

Für eine Weile.

VII

Wer das Licht sehen will

wie es ist

muss zurückweichen

in den Schatten.

VIII

Schatten

Heller als diese Sonne;

Kühler Schatten der Freiheit.

IX

Ganz im Schatten

Verschwindet mein Schatten.

$X$

Im Schatten

ist immer noch Platz. 
DOIS POEMAS E QUATRO EXPOSIÇÕES...

PAULO R. LICHT DOS SANTOS

\section{TRADUÇÃO}

\section{HANS MAGNUS ENZENSBERGER}

\section{O Reino das Sombras}

I.

Aqui vejo ainda um lugar,

um lugar livre,

aqui na sombra.

II.

Esta sombra

não está à venda.

III.

Também o mar

projeta talvez uma sombra,

também o tempo.

IV.

A guerra das sombras

são jogos:

nenhuma sombra

se opõe à outra à luz.

V

Quem mora na sombra,

é difícil de matar.

108 
VI.

Por um instante saio de minha sombra,

por um instante.

VII

Quem quiser ver a luz

como ela é

tem de recuar

para a sombra.

VIII

Sombra

mais clara que este sol:

sombra fresca da liberdade.

IX

$\mathrm{Na}$ sombra inteiro

dissipa-se a minha sombra.

$\mathrm{X}$.

Na sombra

ainda há lugar.

Trad. de Paulo R. Licht dos Santos 
III

\title{
O LEITOR TEMERÁRIO
}

\author{
Wer das Licht sehen will \\ wie es ist \\ muss zurückweichen \\ in den Schatten.
}

H. M. Enzensberger

Os dois poemas de Fichte e de Enzensberger, como já dissemos, são distintos e opostos em muitos aspectos. Basta percorrê-los rapidamente para ver que a diferença de forma se alinha com a contraposição do tema: em Fichte, a questão da unidade da visão e das coisas vistas vêm à luz na tradicional forma do soneto, a "Musa de Arquimedes", como mais tarde irá zombar Tristan Corbière num soneto que é ele próprio uma receita para compor sonetos; ${ }^{1}$ já em Enzensberger, a multiplicidade das coisas vistas se articula como unidade de sombras, um domínio que ele delimita por "versos livres" divididos em pequenos grupos por algarismos romanos - um caso que corporifica a advertência de Eliot de que nenhum verso livre é, ou deveria ser, efetivamente livre -uma libertação da forma².

Se são tão diversos já ao olhar mais imediato, por que justapor os dois poemas? Mero exercício de engenhosidade? Se for assim, talvez tenha razão Philonenko, que, comentando sua própria tradução, acha em Dante o símile de Fichte. Pois tanto o soneto quanto os últimos versos da Divina Comédia exprimiriam em imagens similares o mesmo pensamento de que é a visão divina (o Ser ou o olho de Urânia) que brilha e vê através dos olhos dos homens; assim, tanto um como outro exprimiriam a "essência da intuição intelectual".

\footnotetext{
${ }_{1}^{1}$ Um soneto - com a respectiva receita; veja-se a tradução desse poema por Augusto de Campos, in: Pound, E. Abc da literatura. Trad. de A. Campos e J. P. Paes. São Paulo: Editora Cultrix, 1990, p. 214.

${ }^{2}$ Eliot, T. S. "The music of poetry". In: On Poetry and poets. London-Boston: Faber and Faber, 1986, pp. 26-38.
} 
Mas será que a comparação entre coisas iguais ou de mesmo valor é de fato o único modo de medi-las? Mais do que isso, não seria talvez mais fecundo compreender e avaliar um poema comparando-o com um diferente? Dessa maneira, pelo antagonismo não acabaríamos por delinear um território para a reflexão sobre os dois poemas e, por que não, para a descoberta de algumas propriedades que, de outro modo, passariam despercebidas, seja porque à mais clara luz não exibiriam relevo algum, seja porque se apagariam na noite em que todos os gatos são pardos?

Não há nada de novo nesse procedimento, é apenas a aplicação do método proposto e usado por Ezra Pound no estabelecimento de um "paideuma" e em sua poesia. Pound denomina-o método ideogrâmico, porque consistiria, a exemplo do que Fenollosa teria mostrado em estudo sobre os caracteres chineses, não numa descrição geral e abstrata das coisas ou de poemas, mas na sua apresentação e exame direto:

Em contraste com o método da abstração ou de definir as coisas em termos sucessivamente mais e mais genéricos, Fenollosa encarece o método da ciência, 'que é o método da poesia', distinto do método da 'discussão filosófica', e que é o meio de que se servem os chineses em sua ideografia ou escrita de figuras abreviadas ${ }^{3}$

Não se pode deixar de notar o que há de duvidoso em assimilar uma prática de seleção, análise e construção de poemas a um método indutivo que talvez não vigore nem mesmo nas ciências empíricas. Mas Pound é mais feliz quando num caso particular, deixando de lado a polêmica circunstancial contra a verborragia da filosofia e da crítica literária, se limita a enunciar como preceito geral certa prática, na qual o método da ciência entra apenas como mera metáfora de um procedimento já antes amplamente exercido em outro campo:

Seria particularmente contra o cerne do método ideogrâmico fa-

\footnotetext{
${ }^{3}$ Pound, E. Abc da literatura, p. 26.
} 
zer uma série de considerações gerais em torno da linguagem característica dos poetas isabelinos. O modo certo de estudar a linguagem de Shakeaspeare é estudá-la lado a lado com algo diferente e de igual extensão. O antagonista adequado é Dante, que é de igual porte e diferente (...) É impossível aferir a ação de um produto químico simplesmente acrescentando-lhe um pouco mais do mesmo produto. Para conhecê-lo é preciso conhecer os seus limites, saber o que ele é e o que ele não é. Que substâncias são mais leves ou mais pesadas, mais elásticas ou mais compactas. (...) Impossível medir um produto por si mesmo, diluindoo apenas com alguma substância neutra ${ }^{4}$

Se assim se mostra o espírito da aposta feita aqui, esperando que lançar-se efetivamente à tarefa de comparar os dois poemas antagônicos mostre pelo resultado o acerto do lance, resta ainda uma observação sobre a tradução realizada aqui do poema de Fichte. Reconhecese desde já o fracasso deste tradutor em pelo menos um ponto. Tendo o soneto de Fichte, como explica Philonenko, o troqueu como forma métrica, sua versão mais natural em português seria a do soneto de versos decassilábicos (acento principal na sexta e na décima sílaba). Aqui, porém, foi vertido em versos de dozes sílabas (acento predominante na segunda, quarta, sexta, oitava, décima e décima segunda sílaba), na tentativa de transplantar sem maiores perdas em uma língua diferente o sentido, as imagens e a música do poema original. Afinal, se o soneto de Fichte segue uma tradicional receita dada, não é exatamente por meio dela que Fichte procura ir além do dado, ao seu fundamento e origem ("Ali, à fonte eterna")? Não é através dos versos dispostos numa determinada configuração espacial e através do tempo incorporado no ritmo ("Que, pelo espaço e tempo enleados no tecer") que as palavras acabam por se articular numa imagem (o belo) e exprimir a ordem (o vero) em razão de um ato (o bem) que se volta para o próprio foco uno da visão (o ser)?

Se este tradutor não conseguiu aqui tecer adequadamente numa

${ }^{4}$ Idem, p. 60. 
língua o que foi tramado em outra, trata-se, sem dúvida, de inépcia e, quem sabe, de falta de talento. Ou talvez então, olhando-se para as demais traduções, também se tenha uma prova concreta da resistência incontornável das palavras a toda forma de totalização e de definição. Por isso, não sendo de todo maleáveis à nossa vontade e guardando invariavelmente algum grau de opacidade, acabam sempre por projetar alguma sombra naquilo mesmo que elas fazem ver ou pretendem exprimir: "Também o mar projeta talvez uma sombra/ também o tempo". Não reside nessa sombra e na possibilidade ilimitada de sua projeção a um só tempo o imperativo do dizer e a liberdade do fazer (poiesis)?

\section{Sombra}

mais clara que este sol:

sombra fresca da liberdade. 
DOIS POEMAS E QUATRO EXPOSIÇÕES...

PAULO R. LICHT DOS SANTOS

\section{BIBLIOGRAFIA:}

ENZENSBERGER. H. M. Gedichte 1950-2000. Frankfurt am Main: Suhrkamp Verlag, 2001.

ELIOT, T. S. "The music of poetry", in: On Poetry and poets. London, Boston: Faber and Faber, 1986, p. 26-38.

FICHTE, J. G. Fichtes Werke. Vol. 8. Berlin: Walter de Gruyter:, 1971.

. Doctrine de la Science et textes anexes. Trad. de A. Philonenko. Paris: Vrin, 1987.

Soneto. Trad. de P. C. Souza. In: Folhetim (Folha de São Paulo), nº.593, p.12, 27 maio, 1988.

POUND, E.. Abc da literatura. Trad. de A. Campos e J. P. Paes. São Paulo: Editora Cultrix, 1990. 